\title{
Studier av årsaker til medfødte misdannelser basert på Medisinsk fødselsregister
}

\author{
Rolv T. Lie \\ Institutt for samfunnsmedisinske fag, Universitetet i Bergen og \\ Medisinsk fødselsregister, Nasjonalt folkehelseinstitutt \\ E-post: rolv.lie@smis.uib.no
}

\begin{abstract}
SAMMENDRAG
Studier av årsaker til medfødte misdannelser har helt fra begynnelsen vært et viktig formål med Medisinsk fødselsregister (MFR). Det har sammenheng med at det var Thalidomidkatastrofen med epidemien av medfødte lemmedefekter tidlig på sekstitallet som førte til registerets opprettelse. Her gjennomgåes en rekke studier basert på data fra MFR gjennom registerets førtiårige historie. Studiene spenner fra risiko knyttet til yrkesforhold, kraftlinjer og nedfall etter Tsjernobylkatastrofen til gjentagelsesmønstre innenfor familier. Oversikten vil ikke gi noe forsøk på endelig konklusjon knyttet til disse faktorene, fordi det ville forutsette en total gjennomgang av studier gjort også utenfor Norge. Oversikten dekker heller ikke alle studier med data fra MFR, men er ment å gi et hovedinntrykk av forskning som har benyttet MFR.
\end{abstract}

\section{Lie RT. Studies of causes of birth defects based on the Norwegian Medical Birth Registry. Nor J Epidemiol 2007; 17 (2): 141-146.}

\section{ENGLISH SUMMARY}

Identification of causes of birth defects has been a major purpose of The Norwegian Medical Birth Registry since the registry was started. This has dramatic background in the fact that it was the international epidemic of birth defects caused by the apparently harmless drug Thalidomide that lead to the establishment of the registry in 1967. A review of studies of causes of birth defects based on data from the registry through its 40 year long history is given here. The review spans a variety of studies from studies of occupational exposures, power lines and the Chernobyl fallout to studies of familial recurrence risks. The purpose is not to give a scientific review of current evidence of causal effects but to give an impression of the contribution of the registry to such research over the past 40 years.

\section{INNLEDNING}

En undersøkelse basert på et fødselsregister i Liverpool bekreftet i 1962 mistanker om at legemiddelet Thalidomid forårsaket misdannelser av lemmene (1). Mistanken oppsto opprinnelig i Australia. I ettertid ble det anslått at tusenvis av barn i USA og Europa ble født med alvorlige misdannelser på grunn av Thalidomid som ble gitt til gravide for å dempe kvalme. Erkjennelsen av at registre som førte oversikt over forekomst av misdannelser kunne være et viktig instrument for å oppdage og avklare denne typen epidemier førte til opprettelsen av misdannelsesregistre i en rekke land. Norge var det første landet som fikk et befolkningsdekkende fødselsregister i 1967 (2). Slik registrering og overvåkning har siden vært et viktig formål med Medisinsk fødselsregister i Norge.

Medisinsk fødselsregister har vært involvert i utredning av en rekke såkalte klustre av medfødte misdannelser. Et kluster er en opphopning av flere tilfeller $i$ et avgrenset tidsrom eller et geografisk område, på en arbeidsplass, en skole eller i en annen gruppering hvor folk kjenner seg igjen. Klustre oppdages ofte av dem som er involvert, og skaper bekymring for at tilfellene har årsak i en felles miljøpåvirkning. Sammen med overvåkning av forekomst av misdannelser er beredskap for å kunne belyse klustre i befolkningen er et grunnleggende formål med MFR. Dette forutsetter at datakvaliteten er god. Men forskning har også vært et viktig formål for bruk av dataene i MFR, og verdien av god datakvalitet for slik forskning kan neppe understrekes sterkt nok. Den forskningsmessige utnyttelsen av misdannelsesdataene i MFR har økt sterkt de siste 20 årene, og fremstår som et hovedområde for forskning ved MFR. De er denne aktiviteten som er fokus for gjennomgangen her.

Misdannelser har i hovedsak vært meldt til MFR på grunnlag av diagnoser stilt i første uke etter fødsel. I perioden frem til 1998 ble diagnoser påført MFR's meldeskjema av jordmødre som hadde ansvar for å fylle ut og sende meldeskjemaet i MFR. Diagnoser som ble stilt på et senere tidspunkt eller som ikke var tilgjengelige på fødeavdelingen ved utfylling av meldingen ville derfor ikke bli meldt. Dette førte til en undermeling av enkelte typer diagnoser, særlig diagnoser som ikke alltid stilles like etter fødsel. Etter 1998 har 
registeret hatt en mer ambisiøs registrering, ved at diagnoser fra barneavdelinger og diagnoser som gir grunnlag for abort systematisk skal innhentes. Når et nyfødt barn overføres til en barneavdeling følger MFR-skjemaet med. Barneavdelingen har så ansvar for å melde de medfødte diagnosene som stilles der. Dette har endret registerets karakter fra at fødeavdelingen var eneste kilde for melding til at registeret nå kan motta melding fra flere kilder på samme barn (3).

Detaljert beskrivelse av medfødte misdannelser forutsetter omfattende informasjon om misdannelsenes morfologi og eventuell medisinsk genetisk informasjon. I MFR reduseres denne informasjonen til diagnosekoder som i hovedsak følger ICD-systemet (ICD-8 med tillegg for perioden 1967-98 og IDC-10 for perioden etter 1998). Disse diagnosekodene baserer seg $\mathrm{i}$ hovedsak på at misdannelser $\mathrm{i}$ et organ eller en anatomisk struktur samles i en kategori. Forekomst av slike kategorier har dannet grunnlag for overvåkning og forskning på medfødte misdannelser i MFR.

Kodingen av misdannelser i MFR har i hele perioden vært utført av Rannveig Aardal og Torill Holmar. Stabil spesialkompetanse på dette området har hatt uvurderlig betydning for datakvaliteten ved MFR. Både Lorentz Irgens, Svein Rasmussen og Kari Klungsøyr har engasjert seg i medisinske kodespørsmål og sikret at kodearbeidet har fanget opp de medisinske diagnosene som har vært meldt. Ofte har dette involvert direkte kontakt med de kliniske miljøene.

\section{FOREKOMST OG UNDERRAPPORTERING}

Forekomsten av misdannelser totalt i MFR har ligget nokså stabilt på rundt 3\%. Misdannelser er derfor samlet sett ikke noe sjeldent fenomen. Nærmere 2000 barn og familier i Norge rammes av misdannelser som meldes til MFR hvert år. De aller fleste av disse får aldri noen forklaring på om det var en årsak til at misdannelsen oppsto eller om det hele skyltes en tilfeldighet. Misdannelser varierer mye både når det gjelder hvilken del av kroppen som er berørt og hvor alvorlig skaden er. Hver for seg er de enkelte kategoriene relativt sjeldne. Leppespalte rammer for eksempel 1,5 per 1000 nyfødte i Norge (4).

Ikke alle misdannelser meldes til MFR. Det er grunn til å tro at komplettheten av rapporteringen varierer fra kategori til kategori og antagelig innenfor hver kategori også. En undersøkelse fra 1993 anslo at andelen tilfeller som ble meldt til MFR var henholdsvis $58 \%, 63 \%, 78 \%$ og $91 \%$ for de fire kategoriene Downs syndrom, hypospadi, leppe- og ganespalte og nevralrørsdefekter (5). For tilfeller av både leppe- og ganespalte er det senere beregnet at $79 \%$ er rapportert til MFR, mens tallene var $63 \%$ for leppespalte og $57 \%$ for ganespalte alene $(4,6)$. Rapporteringen varierer imidlertid mye avhengig spaltens omfang og synlighet (7). For eksempel er det bregnet at kun $11 \%$ av milde former for ganespalte er blitt meldt til MFR. Det er grunn til å anta at problemene med melding av mindre alvorlige og mindre synlige misdannelser også gjelder for andre typer misdannelser. En viss grad av underrapportering må man nok regne med $\mathrm{i}$ et befolkningsbasert register, men det er viktig at rapporteringen holdes på et stabilt og høyt nivå. Studier av rapporteringen til MFR av misdannelser etter 1998 er viktige for å kunne bekrefte at rapporteringen er blitt bedre. Flere slike studier er på gang.

\section{TIDSTRENDER}

Den eneste misdannelseskategorien vi med sikkerhet mener har endret forekomst over tid i MFR fra 1967 er bukveggsdefekten gastroscise (8). Denne tidstrenden er også funnet $i$ andre vestlige land, men årsaken er ikke blitt avdekket. Risikoen følger et interessant mønster med høyere risiko blant barn av unge mødre. De senere årene har forekomsten sluttet å øke. For Downs syndrom ble det på åttitallet funnet en øket forekomst blant barn av unge mødre (9) hvor risikoen i utgangspunktet er mye lavere enn for eldre mødre. Noen egentlig årsak til dette forbigående fenomenet er heller ikke funnet.

\section{MILJøFORHOLD OG MISDANNELSER}

Misdannelser kan skyldes både bestemte miljøfaktorer og biologiske forhold som genetikk. Forskning på årsaker til medfødte misdannelser ved MFR kan til en viss grad deles inn i forskning innenfor disse hovedområdene. Denne inndelingen har mange svakheter ved at miljøforhold og biologi egentlig bør sees i sammenheng og studier av for eksempel infeksjoner, som er et litt forsømt område i Norge, ville kunne blitt plassert $\mathrm{i}$ begge områdene.

Det mest dramatiske eksempelet på en årsak i det ytre miljø er fortsatt Thalidomid. Studier av medikamenter har derfor hatt høy prioritet internasjonalt. På grunn av vanskelig tilgang på informasjon om medikamentbruk i Norge har MFR ennå ikke vært brukt til systematisk og omfattende forskning på dette viktige feltet. Det nye reseptregisteret vil kunne føre til en opptrapping av slik forskning.

Et eksempel på en indirekte studie av epilepsimedikamenter og misdannelser i MFR finnes imidlertid (10). Rundt 1980 ble de gamle epilepsimedikamentene fenytoin og fenobarbital langt på vei erstattet av de nyere medikamentene carbamazepin og valproatsyre. Enkelte studier hadde antydet at de gamle medikamentene økte risikoen for leppespalte mens de nyere medikamentene økte risikoen for nevralrørsmisdannelser. Disse effektene ble bekreftet i data fra MFR ved at det blant barn av mødre med epilepsi var en øket risiko for leppespalte før, men ikke etter 1980. For nevralrørsmisdannelser var det en øket risiko kun etter 1980. Disse resultatene er også interessante ved at de knytter risikoen til medikamentene, ikke til det at mor har epilepsi.

Den 26. april 1986 ekspoderte atomreaktor num- 
mer 4 ved Tsjernobylkraftverket i Ukraina. Eksplosjonen og brannen som fulgte slynget store mengder radioaktivt støv opp i atmosfæren. På grunn av værforholdene drev deler av det radioaktive materialet nordvestover og falt som regn i deler av Norge. Særlig øvre Gudbrandsdal, deler av Sørlandet og Midtnorge ble rammet. Bekymring knyttet til helsefare meldte seg raskt, i og med at radioaktiv stråling har kjente helseeffekter. Statens strålevern gjennomførte omfattende målinger i alle kommuner både av det direkte nedfallet på bakken og av radioaktiv forurensing i mat. På grunn av at MFR hadde løpende registrering av forekomst av misdannelser var det mulig å undersøke om de kommunene som hadde fått en økning i strålebelastningen også hadde fått en økning i forekomst av misdannelser (11). Bortsett fra en svak økning i forekomst av vannhode (kombinert med en nedgang i områder med lav strålebelastning) og en uforklarlig nedgang i forekomst av Downs syndrom ble det ikke funnet noen tendens til sammenheng mellom misdannelser og nedfallet fra Tsjernobyl i Norge. Et velfungerende register er viktig for å kunne avklare spørsmål om helserisiko i slike dramatiske situasjoner.

Detaljert geografisk informasjon har også vært brukt $\mathrm{i}$ andre studier. I en studie ble vannkvalitetsinformasjon fra landets vannverk koblet med mottaksadresser $(12,13)$. Barn av mødre som bodde i hus som fikk klorrenset vann under svangerskapet hadde en noe øket forekomst av urinveismisdannelser, men det er vanskelig å trekke noen klare konklusjoner om risiko fra disse studiene.

I en annen studie ble avstand fra alle norske boliger som gravide hadde oppholdt seg i under svangerskapet til nærmeste høyspentledning beregnet. Risiko for misdannelser for hvert svangerskap ble deretter sammenlignet for de som bodde nært og de som bodde fjernt fra ledningene. Studien tydet ikke på noen sammenheng $(14,15)$.

Den klustersaken MFR har vært involvert i som har fått mest offentlig oppmerksomhet er den såkalte KVIKK-saken (16). Et høyt antall misdannelser blant barn av fedre som hadde tjenestegjort på motortorpedobåten MS-KVIKK skapte bekymring for at forhold ombord, spesielt en kraftig radiosignalantenne som ble brukt til støysendinger kunne ha påvirket fedrenes reproduksjonsfunksjon. Flere av tilfellene var imidlertid ikke registrert i MFR og arbeidet ved MFR understreket derfor viktigheten av å ha en god registrering av misdannelser i registeret for å kunne belyse slike saker på en god måte. KVIKK-saken er ikke avsluttet. Den er blant annet blitt belyst gjennom en omfattende arbeidsmiljøundersøkelse i sjøforsvaret (17) og det er uklart hva videre studier vil konkludere med når det gjelder selve saken.

Bekymringen for at radiobølger skulle kunne påvirke fedres reproduksjonsfunksjon ved at deres barn fikk en øket risiko for medfødte misdannelser dannet bakgrunn for at MFR gjennomførte en undersøkelse av fedre som arbeidet i sivile yrker hvor de kunne ha vært utsatt for radiofrekvente elektromagnetiske felt (18). Det ble ikke funnet noen påfallende høy risiko for barn av fedre i slike yrker.

Informasjon om arbeidsforhold, blant annet fra nasjonale folketellingsdata, har vært koblet til MFR i en rekke andre studier. I en studie av yrker med eksponering for lavfrekvente elektromagnetiske felt fant man en antydning til sammenheng mellom nevralrørsmisdannelser og at mor eller far arbeidet i slike yrker (19).

Barn med fedre som arbeidet i trykkeribransjen hvor blyeksponering kan forekomme ble ikke funnet å ha øket risiko for misdannelser (20), mens en nyere studie fant en mulig sammenheng mellom at mødre arbeider med bly og risiko for nevralrørsmisdannelser hos barna (21).

I studier av arbeid i landbruket ble det funnet sammenheng med forekomst av nevralrørsmisdannelser (22) som i en nyere studie er blitt knyttet til mulig bruk av soppmiddelet Mancozeb (23). Disse dataene har også vært med på å avkrefte bekymring som oppsto i England om en sammenheng mellom soppmiddelet Benomyl og øyemisdannelsen anoftalmi (24).

En annen studie som undersøkte tidligere rapporterte sammenhenger fant at fedre med arbeid på bilverksted oftere fikk barn med hypospadi (25). Dette har ikke vært knyttet til bestemte forhold ved yrket. Foreldre med arbeidsplass i fly (hvor det er et høyere nivå av kosmisk stråling) hadde ikke øket risiko for å få barn med misdannelser (26).

En rekke av de studiene som nevnes her er negative ved at de ikke gir noe grunnlag for bekymring om skadelige effekter av yrkes- eller miljøforhold. Slike studier tar ofte utgangspunkt i en bekymring som eksisterer eller en annen vitenskapelig studie som har sett en sammenheng. Gode negative studier kan være meget viktige i slike situasjoner. Men ofte knytter det seg usikkerhet til kvaliteten på informasjonen om miljøforhold og da svekkes også verdien av negative funn.

\section{BIOLOGISKE FORHOLD OG MISDANNELSER}

Mors og fars alder er eksempler på en biologisk faktor som også kan ha sammenheng med livsstil og miljø. Data fra MFR har vært brukt til å beskrive økningen i risiko for Downs syndrom ved økende mors alder (9) og også til å vise at fars alder og mormors alder da mor ble født ikke har betydning $(27,28)$. En studie av gastroscise fant at risikoen økte jo yngre mor var (8). Fars alder har liten betydning for risiko for misdannelser (29).

I en studie som blant annet så spesielt på innvandrerbefolkningen i Norge ble det vist at foreldre som er fetter og kusine har en doblet risiko for å få et barn med misdannelser (30,31). Dette kan skyldes at disse barna i større grad enn andre barn blir homozygote for såkalte recessive alleler. En slik forklaring passer med at disse foreldrene også har en høyere gjentagelsesrisiko for å få enda et barn med misdannelse (32). For 
å gjennomføre en slik studie av gjentagelsesrisiko i MFR må registeret koble sammen barn med samme foreldrene i søskenflokker. Til dette benyttes opplysninger om foreldrenes fødselsnummer i MFR. Etter kobling fjernes alle fødselsnumre fra analysedataene. Familieanalyser av slike koblede data har vært et meget viktig forskningsområde i MFR.

Den første studien som brukte familieinformasjon i MFR til å se på risiko for misdannelser ble publisert så tidlig som i 1984 (33). Studien påviste en høyere risiko blant tvillinger enn hos deres enkeltfødte søsken.

Familier som har fått barn med misdannelser har gjennom historien vært behandlet svært dårlig. De nyeste og kanskje grusomste eksempler på dette er nazistenes behandling av disse familiene under eugenikkprogrammene som gjennom ekteskapsforbud, sterilisering og barmhjertighetsdrap skulle hindre sykdom i å spre seg i befolkningen (34). Grunnlaget for dette var teorier om at slike familier hadde arveanlegg som var skadet og kunne føre til en rekke problemer. Selv om det var kritiske røster, var disse eugeniske teoriene anerkjente over hele Europa i første halvdel av det 20. århundre (35).

Ved å koble sammen norske familier i MFR har det vært mulig å vise for det første at familier som får barn med misdannelser kun har en øket risiko for at det senere skal oppstå en lignende type misdannelse i familien (36-38). Risikoen for at noe annet skal gå galt er samlet sett ikke høyere enn i befolkningen ellers. Fødselsvekten er også helt normal (39). Videre var det mulig å vise at mødre og fedre som selv var født med en misdannelse kun bidrar med $2 \%$ av misdannelsene $\mathrm{i}$ neste generasjon gjennom gjentagelse av en misdannelse hos deres barn. Disse studiene hadde ikke vært mulige uten et stort, langsiktig og befolkningsdekkende register som MFR med muligheter for kobling av familier ved bruk av entydige identfikasjonsnumre. Utnyttelse av disse unike mulighetene bør bli et viktig forskningsområde fremover ettersom befolkningsgrunnlaget og mulighetene for oppfølging og kobling øker. Dette er forskning som både har betydning for helsepolitikk og for veiledning av familier som har opplevd å få barn med misdannelser.

\section{KOBLING MED ANDRE UNDERSØKELSER}

MFR har også vært koblet med andre data i studier av årsaker til misdannelser. Målinger av homocystein i Hordalandsundersøkelsen (HUSK) ble koblet mot MFR i en studie som fant sammenheng med risiko for nevralrørsdefekter og klumpfot (40). Man fant imidlertid ikke at markører for MTHFR-genet hos mødre (som er knyttet til folatmetabolisme og homocystein) fra HUSK-undersøkelsen hadde noen sammenheng med risiko for nevralrørsmisdannelser (41). I en kobling mot data på IVF-svangerskap fant man ingen øket risiko for misdannelser i Norge hos barn som var unnfanget ved den såkalte ICSI-metoden for assistert befruktning (42).

Dataene i MFR bør styrkes med klinisk verifiserte opplysninger når dette er mulig. Gjennom et samarbeid med de to plastikkirurgiske avdelingene som behandler barn med leppe- eller ganespalte i Norge, ble MFR koblet med opplysninger fra alle kliniske journaler fra 1967 til 2001. Disse dataene har gitt detaljert informasjon om forekomst av subkategorier av spalter (43), og vil kunne kaste lys over en rekke forhold knyttet til risiko for spalter. Det er for eksempel viktig å avklare om spalter kan behandles som samlete kategorier som de blir i MFR, eller om mer detaljert kategorisering er nødvendig i studier av årsaker. Gjentagelsesmønstre for mer spesifikke kategorier har også stor betydning for veiledning av familier om fremtidig risiko.

En nasjonal pasient-kontrollstudie av leppe- og ganespalte fra perioden 1996-2001 benyttet MFR for å rekruttere kontroller fra den norske fødepopulasjonen. Denne studien har blant annet knyttet lavt inntak av folat til risiko for leppespalte (44) og er et godt eksempel på hvilken mangfoldig og kraftig forskningsressurs MFR er. Den norske Mor-og-barnstudien er avhengig av MFR som hovedkilde for opplysninger om medfødte misdannelser. Mor-og-barnstudien vil danne et viktig grunnlag for studier av enkelte kategorier av misdannelser. Men det er grunn til å tro at verdien av et norsk medisinsk fødselsregister med gode og verifiserbare opplysninger om medfødte misdannelser vil fortsette å øke i tiden fremover.

\section{REFERANSER}

1. Smithells RW. Thalidomide and malformations in Liverpool. Lancet 1962; i: 1270-3.

2. Bjerkedal T, Bakketeig LS. Surveillance of congenital malformations and other conditions of the newborn. Int J Epidemiol 1975; 4: 31-6.

3. Irgens LM. The Medical Birth Registry of Norway. Epidemiological research and surveillance throughout 30 years. Acta Obstet Gynecol Scand 2000; 79: 435-9.

4. Harville EW, Wilcox AJ, Lie RT, Vindenes H, Abyholm F. Cleft lip and palate versus cleft lip only: are they distinct defects? Am J Epidemiol 2005; 162: 448-53.

5. Lie RT, Heuch I, Irgens LM. Maximum likelihood estimation of the proportion of congenital malformations using double registration systems. Biometrics 1994; 50: 433-44.

6. Harville EW, Wilcox AJ, Lie RT, Abyholm F, Vindenes H. Epidemiology of cleft palate alone and cleft palate with accompanying defects. Eur J Epidemiol 2007; 22: 389-95. 
7. Kubon C, Sivertsen Å, Vindenes HA, Åbyholm F, Wilcox A, Lie RT. Completeness of registration of oral clefts in a medical birth registry: a population-based study. Acta Obst Gyn Scand (Epub 11 Sept 2007).

8. Kazaura MR, Lie RT, Irgens LM, Didriksen A, Kapstad M, Egenaes J, Bjerkedal T. Increasing risk of gastroschisis in Norway: An age-period-cohort analysis. Am J Epidemiol 2004; 159: 358-63.

9. Lie RT, Irgens LM, Heuch I. A temporary increase of Down syndrome among births of young mothers: an effect of risk unrelated to maternal age? Genet Epidemiol 1991; 8: 217-30.

10. Bolton-King P, Lie RT, Irgens LM. Secular changes in the risk of birth defects related to the use of anticonvulsants. Am J Public Health 1996; 86: 1454-6.

11. Lie RT, Irgens LM, Skjærven R, Reitan JB, Strand P, Strand T. Birth defects in Norway by level of external and internal exposure to radiation from Chernobyl. Am J Epidemiology 1992; 136: 377-88.

12. Magnus P, Jaakkola JJ, Skrondal A, Alexander J, Becher G, Krogh T, Dybing E. Water chlorination and birth defects. Epidemiology 1999; 10: 513-7.

13. Hwang BF, Magnus P, Jaakkola JJ. Risk of specific birth defects in relation to chlorination and the amount of natural organic matter in the water supply. Am J Epidemiol 2002; 156: 374-82.

14. Blaasaas KG, Tynes T, Lie RT. Residence near power lines and the risk of birth defects. Epidemiology 2003; 14: $95-8$.

15. Blaasaas KG, Tynes T, Lie RT. Risk of selected birth defects by maternal residence close to power lines during pregnancy. Occup Environ Med 2004; 61: 174-6.

16. Kristensen P, Jacobsen K, Skyberg K. Mefødte misdannelser blant barn med fedre som hadde tjeneste på KNM Kvikk. National Institute of Occupational Health 3/2000: 1-117. Oslo, 2000.

17. Mageroy N, Mollerlokken OJ, Riise T, Koefoed V, Moen BE. A higher risk of congenital anomalies in the offspring of personnel who served aboard a Norwegian missile torpedo boat. Occup Environ Med 2006; 63: 92-7.

18. Mjøen G, Saetre DO, Lie RT, Tynes T, Blaasaas KG, Hannevik M, Irgens LM. Paternal occupational exposure to radiofrequency electromagnetic fields and risk of adverse pregnancy outcome. Eur J Epidemiol 2006; 21: 529-35.

19. Blaasaas KG, Tynes T, Irgens Å, Lie RT. Risk of birth defects by parental occupational exposure to $50 \mathrm{~Hz}$ electromagnetic fields; a population-based study. Occup Environ Med 2002; 59: 92-7.

20. Kristensen P, Irgens LM, Daltveit AK, Andersen A. Perinatal outcome among children of men exposed to lead and organic solvents in the printing industry. Am J Epidemiol 1993; 137: 134-44.

21. Irgens A, Kruger K, Skorve AH, Irgens LM. Reproductive outcome in offspring of parents occupationally exposed to lead in Norway. Am J Ind Med 1998; 34: 431-7.

22. Kristensen P, Irgens LM, Andersen A, Bye AS, Sundheim L. Birth defects among offspring of Norwegian farmers, 1967-1991. Epidemiology 1997; 8: 537-44.

23. Nordby KC, Andersen A, Irgens LM, Kristensen P. Indicators of mancozeb exposure in relation to thyroid cancer and neural tube defects in farmers' families. Scand $J$ Work Environ Health 2005; 31: 89-96.

24. Kristensen P, Irgens LM. Clusters of anophthalmia: No link with benomyl ... or in Norway. BMJ 1994; 308: 205-6.

25. Irgens A, Kruger K, Skorve AH, Irgens LM. Birth defects and paternal occupational exposure. Hypotheses tested in a record linkage based dataset. Acta Obstet Gynecol Scand 2000; 79: 465-70.

26. Irgens A, Irgens LM, Reitan JB, Haldorsen T, Tveten U. Pregnancy outcome among offspring of airline pilots and cabin attendants. Scand J Work Environ Health 2003; 29: 94-9.

27. Kazaura MR, Lie RT. Down's syndrome and paternal age in Norway. Paediatr Perinat Epidemiol 2002; 16: 314-9.

28. Kazaura M, Lie RT, Skjærven R. Grandparents' age and the risk of Down's syndrome in Norway. Acta Obst Gyn Scand 2006; 85: 236-40.

29. Kazaura M, Lie RT, Skjærven R. Paternal age and the risk of birth defects in Norway. Ann Epidemiol 2004; 14: 566-70.

30. Magnus P, Berg K, Bjerkedal T. Association of parental consanguinity with decreased birth weight and increased rate of early death and congenital malformations. Clin Genet 1985; 28: 335-42.

31. Stoltenberg C, Magnus P, Lie RT, Daltveit AK, Irgens LM. Birth defects and parental consanguinity in Norway. Am J Epidemiol 1997; 145: 439-48.

32. Stoltenberg C, Magnus P, Skrondal A, Lie RT. Consanguinity and recurrence risk of birth defects: a population-based study. Am J Med Genet 1999; 82: 423-8.

33. Windham GC, Bjerkedal T. Malformations in twins and their siblings, Norway, 1967-79. Acta Genet Med Gemellol (Roma) 1984; 33: 87-95.

34. Wyszynski DF. Fifty years after the Nuremberg Nazi Doctors' Trial: reviewing how the laws of the Third Reich applied to individuals with oral clefts. Plast Reconstr Surg 1998; 101: 519-27.

35. Melnick M. Cleft lip and palate etiology and its meaning in early 20th century England: Galton/Pearson vs. Bateson; polygenically poor protoplasm vs. Mendelism. J Craniofac Genet Dev Biol 1997; 17: 65-79. 
36. Lie RT, Wilcox A, Skjærven R. A population-based study of recurrence risks of birth defects. $N$ Engl J Med 1994; 331: 1-4.

37. Skjærven R, Wilcox AJ, Lie RT. A population-based study of survival and childbearing among female subjects with birth defects and the risk of recurrence in their children. $N$ Engl J Med 1999; 340: 1057-62.

38. Lie RT, Wilcox AJ, Skjærven R. Survival and reproduction among males with birth defects and the risk of recurrence in their children. JAMA 2001; 285: 755-60.

39. Melve KK, Skjaerven R. Families with birth defects: is birth weight of nonmalformed siblings affected? Am $J$ Epidemiol 2002; 155: 932-40.

40. Vollset SE, Refsum H, Irgens LM, Emblem BM, Tverdal A, Gjessing HK, Monsen AL, Ueland PM. Plasma total homocysteine, pregnancy complications, and adverse pregnancy outcomes: the Hordaland Homocysteine study. Am J Clin Nutr 2000; 71: 962-8.

41. Nurk E, Tell GS, Refsum H, Ueland PM, Vollset SE. Associations between maternal methylenetetrahydrofolate reductase polymorphisms and adverse outcomes of pregnancy: the Hordaland Homocysteine Study. Am $J$ Med 2004; 117: 26-31.

42. Oldereid NB, Abyholm T, Tanbo T, Engelund IE, Irgens LM. Medfødte misdannelser hos barn født etter assistert befruktning i Norge. Tidsskr Nor Laegeforen 2003; 123: 2696-9.

43. Sivertsen $\AA$, Wilcox AJ, Johnson GE, Åbyholm F, Vindenes HA, Lie RT. Prevalence of major anatomic variations in oral clefts. Plastic Reconstr Surg (In Press).

44. Wilcox AJ, Lie RT, Solvoll K, Taylor J, McConnaughey R, Åbyholm F, Vindenes HA, Vollset AE, Saugstad OD, Drevon CA. Folic acid supplement and the risk of facial clefts. BMJ 2007; 334: 464-9. 